\title{
Odor-specific habituation arises from interaction of afferent synaptic adaptation and intrinsic synaptic potentiation in olfactory cortex
}

\author{
Christiane Linster, ${ }^{1,4}$ Alka V. Menon, ${ }^{1}$ Christopher Y. Singh, ${ }^{1}$ and Donald A. Wilson ${ }^{2,3}$ \\ ${ }^{1}$ Computational Physiology Laboratory, Neurobiology and Behavior, Cornell University, Ithaca, New York 14853, USA; \\ ${ }^{2}$ Emotional Brain Institute, Nathan Kline Institute for Psychiatric Research, Orangeburg, New York 10962, USA; ${ }^{3}$ Child and \\ Adolescent Psychiatry, New York University School of Medicine, New York, New York 10016, USA
}

\begin{abstract}
Segmentation of target odorants from background odorants is a fundamental computational requirement for the olfactory system and is thought to be behaviorally mediated by olfactory habituation memory. Data from our laboratory have shown that odor-specific adaptation in piriform neurons, mediated at least partially by synaptic adaptation between the olfactory bulb outputs and piriform cortex pyramidal cells, is highly odor specific, while that observed at the synaptic level is specific only to certain odor features. Behavioral data show that odor habituation memory at short time constants corresponding to synaptic adaptation is also highly odor specific and is blocked by the same pharmacological agents as synaptic adaptation. Using previously developed computational models of the olfactory system we show here how synaptic adaptation and potentiation interact to create the observed specificity of response adaptation. The model analyzes the mechanisms underlying the odor specificity of habituation, the dependence on functioning cholinergic modulation, and makes predictions about connectivity to and within the piriform neural network. Predictions made by the model for the role of cholinergic modulation are supported by behavioral results.
\end{abstract}

Filtering sensory input is critical for information processing tasks such as background segmentation, and shifting processing power away from redundant, stable, or repetitive stimuli toward dynamic, novel stimuli. A critical aspect of this filtering however, is stimulus specificity. Under most circumstances it may be most beneficial to selectively filter the redundant stimulus, while maintaining responsiveness to different, though perhaps highly similar stimuli.

In the olfactory system, short-term habituation to stable or repeated odorants involves a metabotropic glutamate receptor (mGluR)-dependent depression of afferent synapses to the piriform cortex (Best and Wilson 2004). Blockade of group III mGluR receptors prevents cortical adaptation odors (Best and Wilson 2004), and reduces short-term habituation of odor-evoked reflexes (Best et al. 2005) and odor investigation (Yadon and Wilson 2005; Bell et al. 2008; McNamara et al. 2008). This short-term habituation is highly odor specific, with minimal cross-adaptation of piriform cortical single-unit responses or cross-habituation of behavioral responses to similar odors, including between mixtures and their components (Wilson 2000; Cleland et al. 2002). Interestingly, there is an experience-dependent component to shortterm habituation odor specificity. The odor specificity is most pronounced for familiar odors, with very brief $(<20 \mathrm{sec})$ exposure to odors producing more generalization, and longer exposures $(>50 \mathrm{sec})$ sufficient to permit strong odor specificity in cortex adaptation (Wilson 2003).

The homosynaptic nature of afferent synaptic depression underlying cortical adaptation (Wilson 1998; Best and Wilson 2004) may contribute to this odor specificity. However, the experience dependence suggests that there may be an additional process involved. In fact, theoretical views of piriform cortical

${ }^{4}$ Corresponding author.

E-mail CL243@cornell.edu; fax (607) 254-4331.

Article is online at http://www.learnmem.org/cgi/doi/10.1101/lm.1403509. function suggest that the cortex learns previous patterns of input via potentiation of intracortical association fiber synapses (Hasselmo et al. 1990; Barkai et al. 1994; Haberly 2001; Linster et al. 2003). This autoassociative process essentially creates a template of previous network activity, against which new input patterns can be compared, allowing enhanced discrimination between similar patterns, as well as completion of degraded patterns (Barkai et al. 1994; Barnes et al. 2008). In support of this hypothesis, previous work has demonstrated that disruption of normal synaptic potentiation in association fiber synapses through blockade of cholinergic muscarinic receptors (Patil et al. 1998; Linster et al. 2003), reduces odor specificity of cortical adaptation (Wilson 2001b), prevents the effects of odor experience on subsequent behavioral cross-habituation (Fletcher and Wilson 2002), and disrupts odor discrimination (Linster et al. 2001).

The present series of studies further explored the role of combined afferent synaptic depression and intracortical association fiber synaptic potentiation on the specificity of cortical adaptation and odor habituation. Using a computational model of the olfactory system (Linster et al. 2007), the results suggest that activity-dependent association fiber plasticity is necessary to account for the specificity of odor habituation. Furthermore, in behavioral experiments blockade of cholinergic muscarinic receptors during habituation enhances generalization of odor habituation, consistent with the modeling and with previous electrophysiological results.

\section{Results}

\section{Computational modeling}

Olfactory bulb mitral cells and olfactory cortical cells in the computational model (Fig. 1A) displayed a variety of responses to simulated odor stimulation (Fig. 1B,C). When short-term synaptic adaptation was active during prolonged odor stimulation, 
A

B

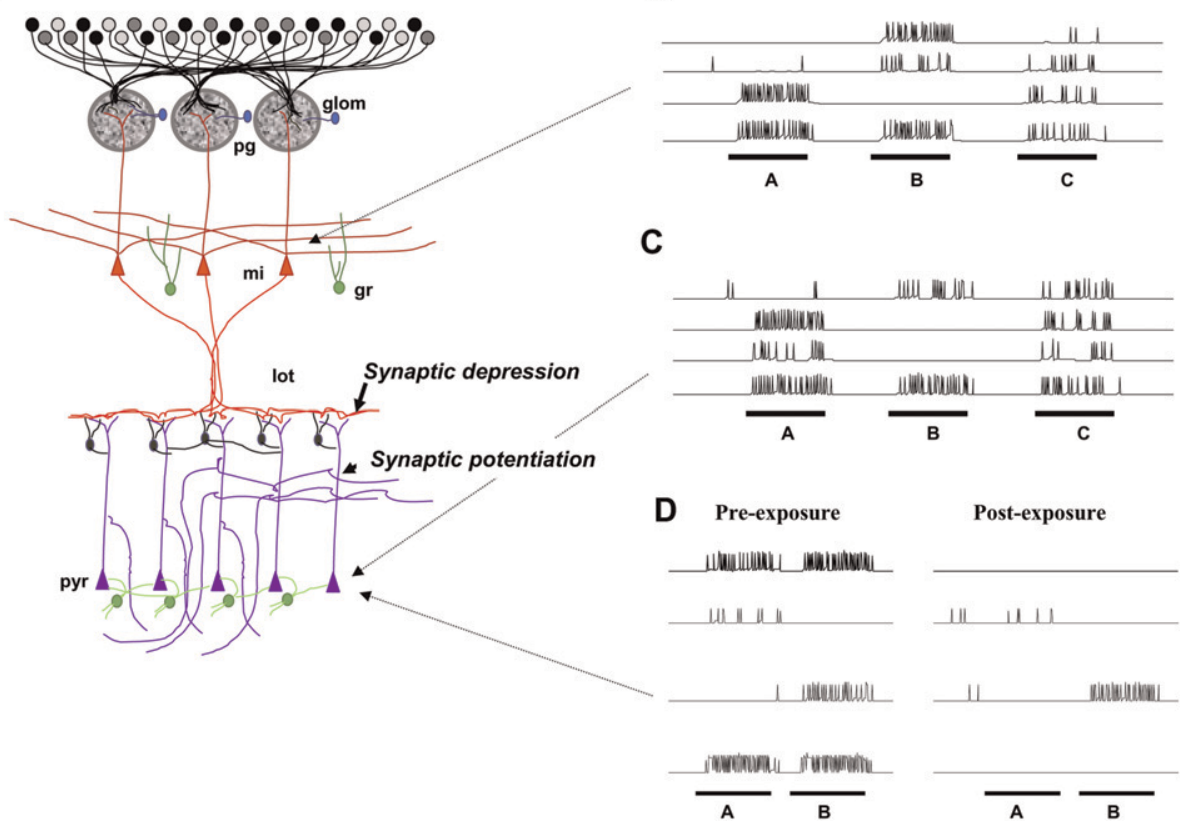

Figure 1. Computational modeling. (A) Schematic structure of the model olfactory bulb and cortex. (B) Example mitral cell responses to three odorants. Each line shows the response of a different cell to three odorants. (C) Example pyramidal cell responses to three odorants. Each line shows the response of a different cell to three odorants. $(D)$ Example pyramidal cell responses to odors A and B before (pre-exposure) and after (post-exposure) prolonged exposure to odor A with only synaptic adaptation active.

piriform cortex pyramidal cells strongly habituated to the exposure odor, as well as to odors activating overlapping populations of olfactory sensory neurons (OSNs) and mitral cells (Fig. 1D). As we have shown before, synaptic adaptation alone, implemented at the mitral-to-pyramidal cell synapse, leads to odor response habituation in pyramidal cells closely matching that observed electrophysiologically and capable of reproducing previous behavioral data showing habituation to background odorants (Linster et al. 2007). However, when odor specificity of the formed habituation is tested by using simulated odorants with a high degree of overlap in OSN activation, simulation results do not show the same specificity as electrophysiological results (Fig. 2A). While habituation to odorants in pyramidal cells recorded in anterior piriform cortex (aPC) is relatively specific (60\% response reduction to habituated odor compared to only $20 \%$ response reduction to chemically similar odorant [Wilson 2000]), response reduction in the simulations is relatively broad. Figure $2 \mathrm{~A}$ shows the ratio of odor responses (sum of all pyramidal cell responses) to a habituated (A) and two similar (B and C, 80\% overlap in OSN activation) odorants before and after prolonged exposure to A. Experimental results have shown that the odor specificity of pyramidal cell habituation depends on working muscarinic cholinergic receptors (Wilson 2001b). In the model, the effect of muscarinic receptor activation on synaptic plasticity within the cortical network (Hasselmo and Barkai 1995; Linster et al. 2003) was represented by activity-dependent synaptic plasticity between pyramidal cells during prolonged odor presentation (i.e., at the same time, but on a slower timescale than activity-dependent synaptic adaptation). Simulations show that when cholinergicdependent synaptic plasticity was turned on ("ON"), prolonged exposure resulted in significantly more odor-specific habituation of the cortical network. Figure $2 \mathrm{~B}$ shows the spiking responses to odors $\mathrm{A}$ and $\mathrm{B}$ of an individual neuron before and after prolonged exposure to odorant $\mathrm{A}$ when potentiation was turned ON or OFF. Figure $2 \mathrm{C}$ shows the average responses of one individual pyrami- dal cell $\left(\mathrm{C}_{\mathrm{i}}\right)$ and the sum of all pyramidal cells $\left(\mathrm{C}_{\mathrm{ij}}\right)$ after prolonged exposure to an odorant as a function of the overlap in OSN activation between the exposed and test odorants. Figure 3 shows examples of odor representations in the cortical model before and after prolonged exposure to an example odorant.

Figure 3 shows the effect of running the simulation for 200 or 1000 sampling steps. Because long-term potentiation (LTP) emerges more slowly than habituation, the odor specificity of habituation develops slower than habituation per se. These simulation results correspond to experimental results on piriform cortex single-unit cross-adaptation to odors (Wilson 2003).

In summary, these results show that implementation of activity-dependent plasticity between pyramidal cells, in addition to synaptic adaptation between mitral and pyramidal cells, leads to odor-specific habituation of pyramidal cell responses in the model (Fig. 4). These results strongly suggest the involvement of the intrinsic association fiber network in the maintenance of odor representations during synaptic adaptation.

\section{Behavioral experiments}

To test if the prediction from electrophysiological and simulation results that functioning muscarinic receptors are necessary to maintain the odor specificity of habituation at a short timescale can be confirmed behaviorally, we ran a behavioral habituation test on mice. Briefly, mice were habituated to a given odor and subsequently presented with novel test odors to test how specific the formed habituation memory is (Fig. 5A). Because a fast timescale habituation paradigm, previously shown to be highly odor specific and mGluR dependent, is used (McNamara et al. 2008), the paradigm is testing the predictions from the electrophysiology and simulations.

\section{Determination of drug dosage}

Because global blockade of muscarinic receptors can have nonspecific effects on investigation and motor behavior, we first tested 
A

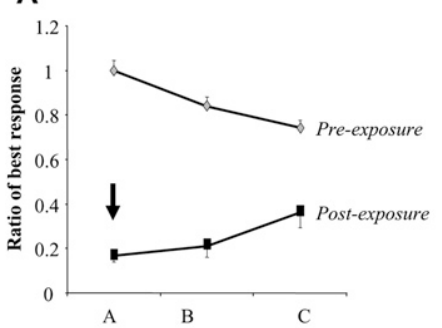

$\mathrm{C}_{\mathrm{i}}$

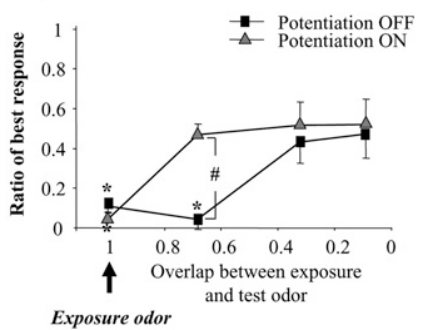

B

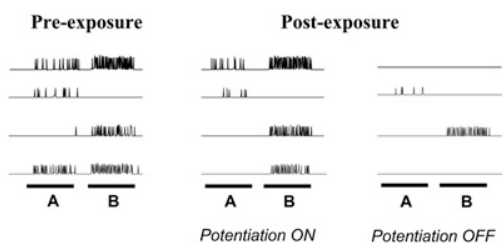

$\mathrm{C}_{\mathrm{ii}}$

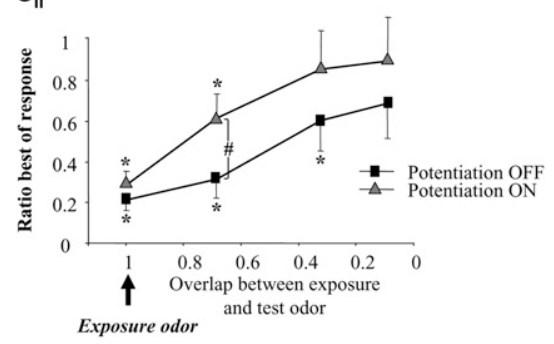

Figure 2. Interaction of adaptation and potentiation. $(A)$ Average responses of all pyramidal cells in the model to three overlapping odorants, A, B, and C, before (pre) and after (post) exposure to odor A with only synaptic depression active. All responses are normalized to the best highest odor response before the exposure and plasticity period. (B) Example pyramidal cell responses to odors A and B before (pre-exposure) and after (post-exposure) exposure to odor A with either adaptation and potentiation active during exposure or only adaptation active. (C) Specificity of habituation with and without synaptic potentiation. $\left(C_{i}\right)$ Average ( \pm standard error) responses of an example pyramidal cell during 50 iterations in response to odors with decreasing amounts of overlap with the habituated (exposure) odor. Curves are normalized to the pre-exposure response to the exposure odor. Note the higher specificity of the habituation, as evidenced by overlapping odorants being less suppressed when adaptation and potentiation act in concert. $\left(C_{i i}\right)$ Average activity in all pyramidal cells in the model during 50 iterations in response to odors with decreasing amounts of overlap with the habituated (exposure) odor. Curves are normalized to the pre-exposure response to the exposure odor.

the mice with a range of dosages using different odorants and the long timescale habituation paradigm to ensure that investigation times per se were not affected by the drugs. We found a significant effect of experimental groups (saline, low scopolamine, medium scopolamine, high scopolamine, and no injection: $F_{(4,180)}=2.595$, $P<0.05)$. A more detailed analysis showed that all groups, except for the group receiving the high dosage of scopolamine, invested the odor significantly less during the last habituation trial than during the first $(P<0.05$ with Tukeys' honestly significant differences [HSD] test), showing that these groups habituated to the odorant (data not shown). These data excluded the higher drug dosage for this experiment because investigation times and habituation performance were impaired. Comparison of the medium-scopolamine group to the saline control and no-injection group showed no significant effect of drug $\left(F_{(2,108)}=3.049 ; P>\right.$ $0.05)$ and post-hoc pairwise comparisons showed no differences between these groups ( $P>0.05$ with Tukey's HSD). As a consequence, we chose to test the mice using the medium dosage of scopolamine $(1 \mathrm{mg} / \mathrm{kg})$ for the following experiments.

\section{Specificity of habituation memory}

In this experiment, all mice were habituated to acetic acid (C2) during four 20-sec trials, separated by 10 -sec intertrial intervals (ITIs). The specificity of the formed memory was then tested by presenting them with a series of gradually chemically dissimilar test odorants differing from the habituated odor by one, two, three, or four carbons (C3, C4, C5, and C6) in randomized order.

When habituation trials were analyzed, no effect of experimental group (saline control and scopolamine) was seen $\left(F_{(1,145)}=\right.$ $0.022, P>0.9)$, whereas a significant effect of trial was observed $\left(F_{(3,145)}=16.402, P<0.001\right)$. Post-hoc comparisons showed a significant effect of trial (saline control: $F_{(3,72)}=9.076, P<0.001$; scopolamine: $\left.F_{(3,73)}=7.633, P<0.001\right)$ as well as successful habituation (significant decrease of investigation between first and last habituation trial, $P<0.001$ ) in both experimental groups. We concluded that global injections of $1 \mathrm{mg} / \mathrm{kg}$ scopolamine had no effect on the mice's ability to habituate to acetic acid over the course of four 20 -sec trials separated by 10 -sec ITIs (Fig. 5Bi).

To test for the specificity of the habituation memory, investigation times during the last habituation trial were compared to those during test trials with novel odorants of increasing chemical dissimilarity. Significant effects of experiment group (saline control or scopolamine, $\left.F_{(1,103)}=4.083, P<0.05\right)$ and odor $\left(\mathrm{C} 2, \mathrm{C} 3, \mathrm{C} 4, \mathrm{C} 5, \mathrm{C} 6, F_{(4,49)}=4.486\right.$, $P<0.01)$ were observed. Post-hoc analysis showed a significant effect of trial in the saline control group $\left(F_{(4,49)}=3.318, P<\right.$ 0.01 ) with mice investigating $\mathrm{C} 4, \mathrm{C} 5$, and C6 significantly more than the habituated odor, C2. In contrast, no significant effect of trial was observed in scopolamine treated mice $\left(F_{(4,54)}=0.05, P>0.3\right)$ and mice investigated only odor C5 significantly more than the habituated odor C2 $(P<0.05)$. We concluded from these data that blockade of muscarinic receptor activation via global injections of scopolamine significantly decrease the odor specificity of the habituation memory, as predicted from the modeling results (Fig. 5Bii).

\section{Long timescale control}

In this experiment using a long-term habituation protocol previously shown to depend on olfactory bulbar rather than cortical processing (McNamara et al. 2008), mice were habituated to acetic acid (C2) during four 50-sec trials, separated by 5-min ITIs (Fig. 6A). The specificity of the formed memory was then tested by presenting them with a series of gradually chemically dissimilar test

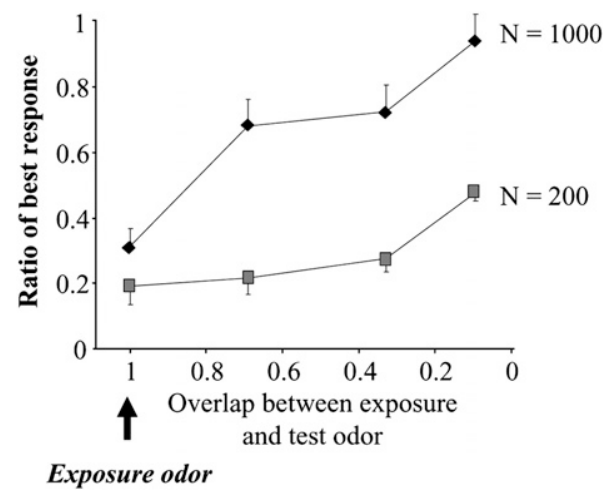

Figure 3. Time course of habituation and odor specificity. The graph shows the average responses of pyramidal cells in response to odors with decreasing overlap with the habituated (exposure odor), using 200 or 1000 iterations of the model during exposure. The curves are normalized with respect to the response to pre-exposure response to the exposure odor. Note that after 200 iterations the odor specificity of habituation is substantially less than after 1000 iterations. 


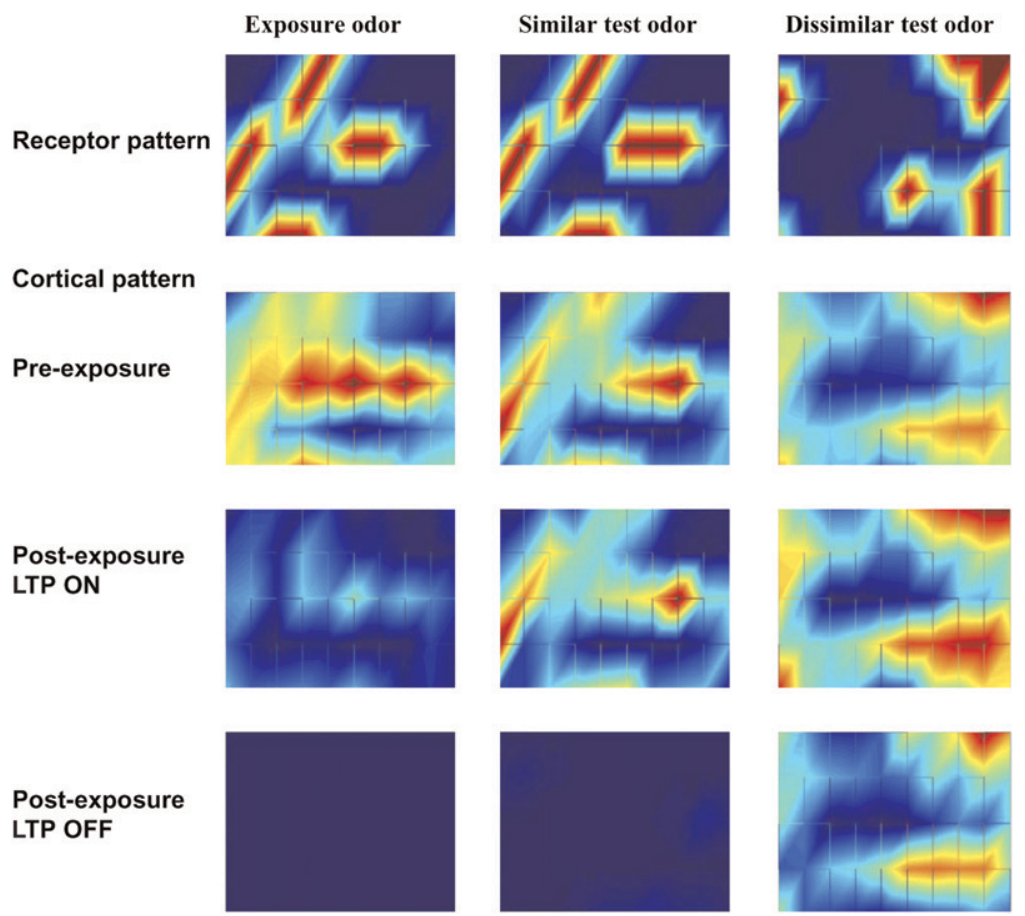

Figure 4. Odor representations in the cortical model. The panels illustrate the responses of the model to three simulated odorants, two highly overlapping in their receptor activation pattern (exposure and similar test odor) and two nonoverlapping (exposure and dissimilar test odor). The graphs show a twodimensional, color-coded representation of the relative activation of OSNs (receptor pattern) and pyramidal cells (cortical pattern) in response to the three odorants, with warmer colors indicating higher activation levels. Note that the dark blue color indicates the lowest response amplitudes, not necessarily zero spiking activity. Responses to each odorant in the cortical cells are shown in the "naïve" model (pre-exposure), as well as after synaptic plasticity in both layers (post-exposure, LTP on) or in only mitral-to-pyramidal synapses (LTP OFF). Note the high degree of response adaptation seen in the cortical layer when intrinsic fiber LTP is turned off.

odorants differing from the habituated odor by one, two, three, or four carbons (C3, C4, C5, and C6) in randomized order.

When habituation trials were analyzed, no effect of experimental group (saline control and scopolamine) was seen $\left(F_{(1,137)}=\right.$ $0.865, P>0.3)$, whereas a significant effect of trial was observed $\left(F_{(3,137)}=8.285, P<0.001\right)$. Post-hoc comparisons showed a significant effect of trial for both groups (saline control: $F_{(3,69)}=$ 4.841, $P<0.01$; scopolamine: $\left.F_{(3,68)}=4.522, P<0.01\right)$, as well as significant habituation (significant decrease in investigation between first and last habituation trial $(P<0.01$ in both groups; Fig. 6Bi).

To test for the specificity of the habituation memory, investigation times during the last habituation trial were compared to those during test trials with novel odorants of increasing chemical dissimilarity. In this paradigm, no significant effect of experimental group (saline control or scopolamine, $F_{(1,95)}=0.005$, $P>0.9)$ or odor $\left(\mathrm{C} 2, \mathrm{C} 3, \mathrm{C} 4, \mathrm{C} 5\right.$, and C6, $F_{(4,95)}=0.175, P>0.1$; Fig. 6Bii) were observed. These data show that global blockade of muscarinic receptors did not affect the formation or specificity of habituation memory when the longer timescale paradigm was used. The observed difference in specificity between the two timescales agrees with that reported previously by our laboratories (McNamara et al. 2008).

\section{Discussion}

The present results suggest that the high degree of stimulus specificity observed in piriform cortical and behavioral short-term odor habituation is dependent on plasticity of intracortical asso- disrupt odor specificity of short-term odor habituation.

\section{Cortical plasticity and odor perception}

Different odors excite unique combinations of olfactory sensory neurons (Duchamp-Viret et al. 1999; Malnic et al. 1999), which in turn activate unique spatiotemporal patterns of second-order mitral cells in the olfactory bulb (Imamura et al. 1992; Davison and Katz 2007). Mitral cell axons, in turn, form the direct sensory afferent to the piriform cortex in the form of distributed, overlapping projections (Ojima et al. 1984; Buonviso et al. 1991). The distributed afferent input allows convergence onto individual pyramidal neurons of input from mitral cells responding to different sensory neurons (Franks and Isaacson 2006), and the beginnings of a read-out of combinatorial sensory input.

The process of odor feature recombination in the piriform cortex is further enhanced through the intracortical association fibers. Individual pyramidal neurons can connect with over 1000 other pyramidal neurons scattered across the piriform cortex (Johnson et al. 2000). The data reported here further establishes synaptic plasticity within this association fiber system as a critical component of odor discriminating properties of piriform cortical circuitry. The results support the hypothesis that the piriform cortex is an autoassociative array that learns previously experienced odor-specific combinatorial patterns of mitral cell input. This learning occurs through associative plasticity of intracortical association fiber synapses between cortical pyramidal cells and establishes templates of familiar patterns. Thus, through the activation of afferent synapses and subsequent activation of learned templates, exposure to similar or overlapping patterns 
A

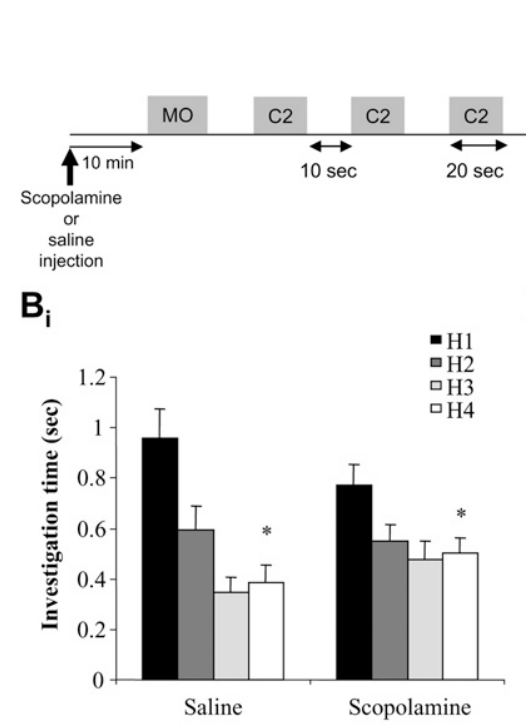

$B_{\text {ii }}$

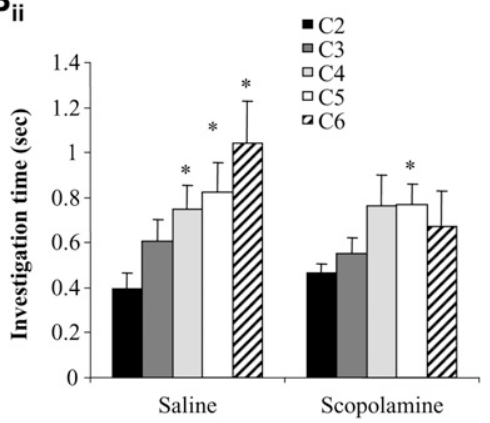

Figure 5. Behavioral results. (A) Experimental design. Testing started $10 \mathrm{~min}$ after injections (saline or drug). On any given day, mice were presented with a tea ball scented with the carrier, mineral oil (MO), the habituation odor $\mathrm{C} 2$ four times and two out of the four test odors (C3-C6) in sequential 20-sec trials separated by 10 -sec ITIs. (B) Results from short ITI experiments. $\left(B_{i}\right)$ Habituation trials. The graph shows the average investigation times of mice injected with saline or $1 \mathrm{mg} / \mathrm{kg}$ scopolamine in response to repeated presentations of acetic acid separated by 10 -sec ITIs. Note that both groups habituated to the odorant, as evidenced by a significant decrease in investigation time between the first and fourth trial. $\left(B_{i i}\right)$ Investigation time in response to the last habituation trial (acetic acid, C2) and the four test trials (C3-C6) using odors differing by one to four carbons from acetic acid. Note that saline injected mice are cross-habituated to only C3, whereas scopolamine injected mice are cross-habituated to all test odorants except $\mathrm{C} 5$.

allows either pattern completion (i.e., match) and behavioral generalization or pattern separation (decorrelation; i.e., mismatch) and behavioral discrimination.

In stable-odor environments, homosynaptic depression of afferent cortical synapses allows filtering of background odors (Best and Wilson 2004) and maintained responses to other markedly different odors, which activate a different, nondepressed set of afferents (e.g., odors presented against the background [Kadohisa and Wilson 2006; Linster et al. 2007]). However, in situations where two familiar odors share similar, potentially overlapping sets of features and afferent input synapses, the modeling results (Figs. 2, 4) show that the previously strengthened association synapses allow pattern completion and reduced generalization between the similar inputs, i.e., limited cross-adaptation.

Given this model, it was predicted that degradation of association fiber synaptic plasticity should disrupt odor discrimination and enhance cross-adaptation between similar odors. Previous work has shown that disruption of cholinergic input to the piriform cortex enhances cross-adaptation of piriform cortex pyramidal cell single-unit responses to odors (Wilson 2001b) and impairs olfactory perceptual learning (Fletcher and Wilson 2002). The modeling results here show that this impairment of singleunit odor processing can be accounted for by acetylcholine's impact on association fiber synaptic plasticity.

\section{Summary}

Acetylcholine modulates neural circuit function in both the olfactory bulb and piriform cortex (Barkai et al. 1994; Linster et al. 1999; Turchi and Sarter 2000; Chaudhury et al. 2009), either or both of which could impact odor discrimination. For example, changes in either olfactory bulb odor-specific pattern generation (Grajski and Freeman 1989; Linster and Cleland 2002; Fletcher and Wilson 2003; Mandairon et al. 2006b; Chaudhury et al. 2009), or piriform cortical pattern recognition could affect odor perception. The present findings, combined with past experiments with localized manipulations of piriform cortex cholinergic activity (Wilson 2001b), support an important role for cholinergic modulation of cortical network plasticity in odor discrimination.

\section{Materials and Methods}

\section{Computational modeling}

We used a computational model of olfactory sensory neurons, olfactory bulb, and piriform cortex (Fig. 1A). The individual elements of this model have been described in detail before (Linster and Hasselmo 2001; Linster and Cleland 2002, 2004; Linster et al. 2003) and have been interconnected for the present purposes (Linster et al. 2007). Olfactory sensory neurons and olfactory bulb mitral cells exhibited odor responses similar to those described experimentally and the olfactory bulb model also exhibited weak odor-evoked oscillations in the gamma-frequency range. Distributions of projections between olfactory bulb output neurons and piriform cortex pyramidal cells, as well as the synaptic adaptation between these two structures (Wilson 1998, 2001a, 2003) were adjusted to yield pyramidal cell odor responses and adaptation properties representative of those described experimentally.

Briefly, simulated odorants each activate a subset of OSNs in the model, drawn randomly with the degree of activation defined by a normally distributed response profile centered on one of the OSNs and standard deviation of one $\left(\sigma_{R}=1\right)$. Each OSN, representing the population of OSNs expressing a given receptor, activated mitral and periglomerular cells in a single olfactory bulb glomerulus. Bulbar computations were those described previously with parameters detailed in Table 1 (Linster and Cleland 2002, 2004; Linster et al. 2007).

In a model simulating 50 OSNs, 50 mitral (Mi), granule (Gr), periglomerular (PG), and 50 pyramidal (Pyr) cells, synapses between mitral and pyramidal cells were created randomly with each mitral cell projecting to any pyramidal cell with an equal probability of $P_{\text {Mit-Pyr }}=0.2$. Within the cortical model, pairs of pyramidal cells connected with the same uniform probability $P_{\mathrm{Pyr}}=$ 0.2 across the model, and these synapses were subject to activitydependent potentiation as described experimentally (Jung and Larson 1994; Hasselmo and Barkai 1995; Chaillan et al. 1996; Kapur and Haberly 1998; Patil et al. 1998).

Both olfactory bulb and piriform cortex models are simplified representations of known olfactory circuitry constructed pursuant to the goal of determining the functional role of activitydependent short-term synaptic depression between olfactory bulb mitral cells and piriform cortex pyramidal cells, paired with activity-dependent potentiation of the synapses between pyramidal cells. Hence, these models omit a number of established anatomical and pharmacological details, which would not materially affect the outcome of the present simulations. All neurons were represented as single compartments except for mitral cells, which were represented by two compartments (the primary dendritic arborization and the soma with secondary dendrites). Each compartment was characterized by a membrane time constant, which can be regarded as the mean product of the membrane capacitance and the membrane input resistance. 
A

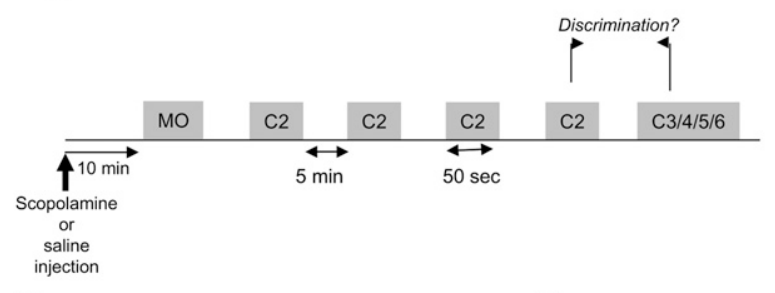

$\mathbf{B}_{\mathbf{i}}$

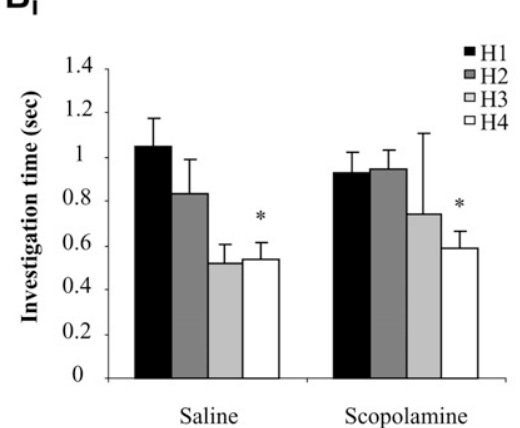

$\mathbf{B}_{\mathrm{ii}}$

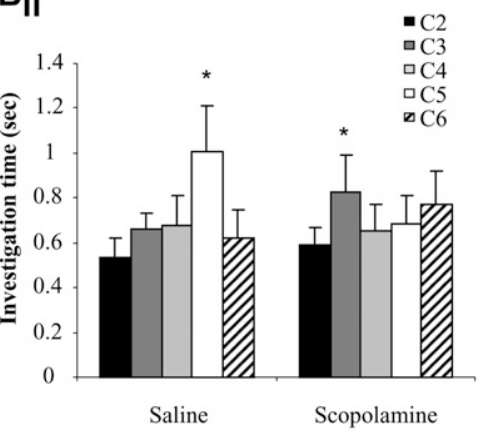

Figure 6. Behavioral results, long timescale comparison. (A) Experimental design. Testing started 10 min after injections (saline or drug). On any given day, mice were presented with a tea ball scented with the carrier, mineral oil (MO), the habituation odor $C 2$ four times and two out of the four test odors (C3C6) in sequential 50-sec trials separated by 5-min ITIs. (B) Results from long ITI experiments. $\left(B_{i}\right)$ Habituation trials. The graph shows the average investigation times of mice injected with saline or 1 $\mathrm{mg} / \mathrm{kg}$ scopolamine in response to repeated presentations of acetic acid separated by 5 -min ITIs. Note that both groups habituated to the odorant, as evidenced by a significant decrease in investigation time between the first and fourth trial. $\left(B_{i i}\right)$ Investigation time in response to the last habituation trial (acetic acid, $\mathrm{C} 2$ ) and the four test trials ( $\mathrm{C} 3-\mathrm{C} 6$ ) using odors differing by one to four carbons from acetic acid. Note that no difference in performance between saline injected control animals and scopolamine injected experimental animals was observed.

Consequently, the evolution of the membrane voltage over time is described by a first-order differential equation:

$$
\tau \frac{\mathrm{dv}(\mathrm{t})}{\mathrm{dt}}+\mathrm{v}(\mathrm{t})=\mathrm{I}_{\text {ext }}(t),
$$

where $\tau$ is the charging time constant of the neuron and $I_{\text {ext }}(t)$ is the total input at time $t$. The input from a particular presynaptic neuron at time $t$ is computed as a function of the synaptic strength $w_{i j}$, the conductance change $g(t)$ due to a presynaptic event $x_{i}\left(t_{0}\right)$ at time $t_{0}$, and the difference between the Nernst potential $E_{\mathrm{N}, i j}$ of the associated channel type and the current membrane potential $v_{j}(t)$ of the postsynaptic neuron:

$$
\mathrm{I}_{\mathrm{j}, \text { ext }}(t)=\sum_{\mathrm{i}} \mathrm{W}_{\mathrm{ij}} g\left(X_{i}\left(t_{o}\right)\right)\left[E_{N, i j}-v_{j}(t)\right] .
$$

The time course of $g(t)$ is described by a double exponential function:

$$
\mathrm{g}(\mathrm{t})=\mathrm{x}_{\mathrm{i}}\left(\mathrm{t}_{0}\right) \mathrm{g}_{\max } \frac{\tau_{1} \tau_{2}}{\tau_{1}-\tau_{2}}\left(\mathrm{e}^{-\left(\mathrm{t}-\mathrm{t}_{0}\right) / \tau_{1}}-\mathrm{e}^{-\left(\mathrm{t}-\mathrm{t}_{0}\right) / \tau_{2}}\right) .
$$

All neurons in the model produced discrete spikes of unit amplitude for output, computed according to the instantaneous spiking probability, a continuous, bounded function of the membrane potential with a threshold $\theta_{\min }$ and a saturation value $\theta_{\max }$. When networks are built, all parameters are chosen randomly $\pm 10 \%$ around the mean values indicated in Table 1 to ensure that the results are not based solely on a specific combination of parameters. All graphs that show average simulation results have been obtained with at least 10 different network realizations with randomly chosen parameters.

In the simulations presented here, as in our previous simulations (Linster et al. 2007), we varied the impact of mitral cell outputs onto pyramidal cell dendrites in an activity-dependent manner during prolonged odor presentation. Synaptic strengths

were first calculated from the parameters given in Table 1, and responses to simulated odorants were obtained. These responses correspond to the pre-exposure responses in electrophysiological experiments described elsewhere (Wilson 1998, 2001b, 2003; Best and Wilson 2004). To simulate synaptic depression due to prolonged exposure to an individual odorant, the network was stimulated with an odorant and an activity-dependent plasticity rule was implemented to simulate synaptic depression due to prolonged exposure:

$$
w_{i j}^{\text {post }}=w_{i j}^{\text {pre }} * \alpha / \sum_{t=1}^{N} x_{j}(t),
$$

where $w_{i j}$ is the synaptic strength between the presynaptic mitral cell $j$ and the postsynaptic pyramidal cell $i, \alpha$ is the rate of depression, and $x_{j}(t)$ is the output of the presynaptic mitral cell. Short-term synaptic depression thus depends only on presynaptic activity and is synapse specific, as has been shown experimentally. Prolonged odor exposure is simulated by calculating the post-exposure synaptic weight during a 0.5 -sec odor exposure, with $\alpha$ set to 0.2 . Note that longer exposure times, as used in the electrophysiology experiments, with a lower rate of depression would lead to the same degree of depression.

In simulations during which synaptic potentiation within the cortical network was "ON," corresponding to control conditions without pharmacological blockade of muscarinic cholinergic receptors, intrinsic excitatory synapses between pairs of odor responsive pyramidal cells underwent synaptic potentation:

$$
w_{i j}^{\text {post }}=w_{i j}^{\text {pre }} * \eta * \sum_{t=1}^{N} x_{j}(t)
$$

where $w_{i j}$ is the synaptic strength between the presynaptic pyramidal cell $j$ and the postsynaptic pyramidal cell $i, \eta=1.6$ is the rate of potentiation, and $x_{j}(t)$ is the output of the presynaptic pyramidal cell. This potentiation rule leads to a self-organized representation in which pyramidal cells that are not responsive to an odorant are recruited to participate in an odor representation and has been shown to be modulated by activation of muscarinic cholinergic receptors (Linster et al. 2003).

To determine the odor specificity of the simulated habituation process, we calculated the ratio of the total number of spikes evoked by an odorant (habituation or test odorant) before and after the habituation exposure (i.e., period of plasticity in the model). Odor-specific habituation, as shown experimentally, results in the response to the habituated odorant being significantly more suppressed than the response to chemically and perceptually related test odorants. Based on our understanding of the relationship between perceptual and neural response similarity (Cleland et al. 2002; Linster et al. 2002), we simulated perceptual similarity by high overlap in OSN responses to a pair of odorants. Overlap is calculated as the normalized dot product between the OSN activation patterns to the two odorants (Linster and Hasselmo 1997; Linster and Cleland 2002; Mandairon et al. 2006a). Hence, the degree of habituation was plotted as a function of the OSN response overlap between the habituated and the test odorant.

\section{Behavioral experiments}

To test if odor specificity of habituation at the timescale observed in electrophysiological responses of cortical neurons depends on 
Table 1. Model parameters

\begin{tabular}{|c|c|}
\hline Olfactory sensory neurons (OSN) & $\tau=5.0 \mathrm{~ms} ; \theta_{\min }=0.0 ; \theta_{\max }=1.0$ \\
\hline $\begin{array}{l}\text { Periglomerular cells (PG) } \\
\text { Mitral cells (Mi) } \\
\text { Granule cells (Gr) } \\
\text { Pyramidal cells } \\
\text { Feedforward IN } \\
\text { Feedback IN } \\
\text { Afferent, OSN to PG } \\
\text { Afferent, OSN to Mi } \\
\text { Intraglomerular inhibitory, PG to Mi } \\
\text { Intraglomerular excitatory, Mi to PG } \\
\text { Interglomerular inhibitory, PG to Mi ( } \pm 5 \text { neighboring glomeruli) } \\
\text { Secondary dendrites, Mi to Gr ( } 20 \text { neighboring granule cells; } \\
\text { WMi-Gr decays linearly with distance) } \\
\text { Feedback inhibitory, Gr to Mi (10 neighboring mitral cells) } \\
\text { Feedback inhibitory, Gr to Gr (5 neighboring granule cells) } \\
\text { Mitral cell to pyramidal cell } \\
\text { Pyramidal cell association fibers } \\
\text { Feed-forward inhibition } \\
\text { Feedback inhibition }\end{array}$ & $\begin{array}{l}\tau=2.0 \mathrm{~ms} ; \theta_{\min }=0.2 ; \theta_{\max }=1.0 \\
\tau=20.0 \mathrm{~ms} ; \theta_{\min }=-0.01 ; \theta_{\max }=8.0 \\
\tau=4.0 \mathrm{~ms} ; \theta_{\min }=-0.1 ; \theta_{\max }=4.0 \\
\tau=10.0 \mathrm{~ms} ; \theta_{\min }=-0.01 ; \theta_{\max }=4.0 \\
\tau=5.0 \mathrm{~ms} ; \theta_{\min }=-0.01 ; \theta_{\max }=8.0 \\
\tau=5.0 \mathrm{~ms} ; \theta_{\min }=-0.01 ; \theta_{\max }=8.0 \\
W_{\mathrm{OSN}-\mathrm{PG}}=0.003 ; E_{\mathrm{N}, \mathrm{OSN}-\mathrm{PG}}=+70 ; t_{1}=1.0 ; t_{2}=2.0 \\
W_{\mathrm{OSN}-\mathrm{Mi}}=0.014 ; E_{\mathrm{N}, \mathrm{OSN}-\mathrm{Mi}}=+70 ; t_{1}=1.0 ; t_{2}=2.0 \\
W_{\mathrm{PG}-\mathrm{Mi}}=0.0001 ; E_{\mathrm{N}, \mathrm{PG}-\mathrm{Mi}}=-5 ; t_{1}=4.0 ; t_{2}=8.0 \\
W_{\mathrm{Mi}-\mathrm{PG}}=0.0001 ; E_{\mathrm{N}, \mathrm{Mi}-\mathrm{PG}}=70 ; t_{1}=1.0 ; t_{2}=2.0 \\
W_{\mathrm{PG}-\mathrm{Mi}}=0.0015 ; E_{\mathrm{N}, \mathrm{PG}-\mathrm{Mi}}=-5 ; t_{1}=4.0 ; t_{2}=8.0 \\
W_{\mathrm{Mi}-\mathrm{Gr}}=0.006 ; E_{\mathrm{N}, \mathrm{Mi}-\mathrm{Gr}}=70 ; t_{1}=1.0 ; t_{2}=2.0 \\
\\
W_{\mathrm{Gr}-\mathrm{Mi}}=0.0015 ; E_{\mathrm{N}, \mathrm{Gr}-\mathrm{Mi}}=-5 ; t_{1}=4.0 ; t_{2}=8.0 \\
W_{\mathrm{Gr}-\mathrm{Gr}}=0.014 ; E_{\mathrm{N}, \mathrm{Gr}-\mathrm{Gr}}=-5 ; t_{1}=4.0 ; t_{2}=8.0 \\
P=0.2 ; \sigma=5 ; W_{\mathrm{Mi}-\mathrm{Pyr}}=0.028 ; E_{\mathrm{Mi}-\mathrm{Pyr}}=70 ; t_{1}=1.0 ; t_{2}=2.0 \\
P=0.1 ; W_{\mathrm{Pyr}-\mathrm{Pyr}}=0.0001 ; E_{\mathrm{Pyr}-\mathrm{Pyr}}=70 ; t_{1}=1.0 ; t_{2}=2.0 \\
W_{\mathrm{ff}-\mathrm{Pyr}}=0.0001 ; E_{\mathrm{ff}-\mathrm{Pyr}}=-5 ; t_{1}=4.0 ; t_{2}=8.0 \\
W_{\mathrm{fb}-\mathrm{Pyr}}=0.0015 ; E_{\mathrm{fb}-\mathrm{Pyr}}=-5 ; t_{1}=4.0 ; t_{2}=8.0 \\
W_{\mathrm{Pyr} f \mathrm{fb}}=0.0015 ; E_{\mathrm{Pyr} f \mathrm{fb}}=70 ; t_{1}=1.0 ; t_{2}=2.0\end{array}$ \\
\hline
\end{tabular}

functioning muscarinic receptors in vivo, we tested mice in a behavioral experiment. We have previously shown that when habituated at the timescale employed during electrophysiological experiments, using very short intertrial intervals (ITI, $20 \mathrm{sec}$ ), mice exhibited highly specific habituation memory when compared to mice habituated with longer (5 min) ITIs (McNamara et al. 2008). We test here how the odor specificity is affected by blockade of muscarinic receptors using the short ITI paradigm.

\section{Subjects}

A total of 10 male CD-1 mice (Charles River), aged 2 mo at the beginning of the study, served as subjects. Mice were housed in groups of 3-4 in standard laboratory cages and kept on a reversed 12:12 light cycle. Food and water were available ad libitum. All experiments were carried out under a protocol approved by the Cornell University Institutional Animal Care and Use Committee in accordance with NIH guidelines.

\section{Odors}

For measurements of the specificity of habituation memory (see Behavioral testing), we used a homologous series of straight-chain carboxylic acids including acetic acid, propanoic acid, $n$-butanoic acid, $n$-pentanoic acid, and $n$-hexanoic acid (Sigma-Aldrich). All odors were diluted with mineral oil to achieve a theoretical vaporphase partial pressure of 1.0 Pa (Cleland et al. 2002); corresponding volume/volume dilutions are listed in Table 2 . For odor presentations, $60-\mu \mathrm{L}$ aliquots of diluted odorant or plain mineral oil were deposited onto filter paper and then placed inside a tea ball.

\section{Behavioral testing}

Mice were tested at $1100 \mathrm{~h}, 2 \mathrm{~h}$ into their dark cycle. For testing, mice were separated into individual plastic cage boxes without bedding or food. For testing of nonspecific drug effects on sniffing behavior and investigation times, we used a long ITI protocol to be able to observe the behavior in detail. This protocol consists of 50sec odor presentations separated by 5-min ITIs (McNamara et al. 2008). To test for drug effects on odor specificity of short-term habituation memory, we used the short timescale paradigm consisting of 20 -sec odor presentations separated by 10 -sec ITIs (Fig. 5A).

In a given session, mice were first presented with a tea ball scented with the carrier (mineral oil, MO) only. They were then presented with the habituation odorant (C2) during four successive trials $(\mathrm{H} 1-\mathrm{H} 4)$. Subsequently, they were presented with two test odorants, randomly chosen from the four test odorants used (propanoic acid or C3, $n$-butanoic acid or C4,n-pentanoic acid, or C5 and $n$-hexanoic acid or C6). The experimenter was blind to the identity of the test odorants.

To allow for testing of all four test odorants under both drug conditions, each mouse underwent a total of four habituation sessions separated by at least $2 \mathrm{~d}$. All four test odorants were thereby presented according to a counterbalanced schedule. Habituation series were separated by at least $48 \mathrm{~h}$ to minimize cumulative effects. We have previously shown that habituation memory at this timescale lasts no longer than 10-20 min (McNamara et al. 2008).

\section{Drugs}

We first tested for nonspecific effects of global injections of the muscarinic antagonist scopolamine using three dosages reported to be effective in olfactory tasks in the literature (Ravel et al. 1992; De Rosa and Hasselmo 2000). Mice were injected i.p. with 0.5, 1, or $5 \mathrm{mg} / \mathrm{kg}$ scopolamine (scopolamine hydrochloride, SigmaAldrich) diluted in saline for a final injection volume of $0.1 \mathrm{~mL}$ for $10 \mathrm{~g}$ of body weight. For the final experiment, mice were injected with $1 \mathrm{mg} / \mathrm{kg}$ scopolamine. All injections were given 20 min before the behavioral session began. Mice were shaped for 2 wk prior to the experiments by having tea balls and odorants in their cages and by receiving injections of saline.

\section{Data analysis}

All data were recorded as investigation time in seconds. Data were plotted using Microsoft Excel (Microsoft Corporation) and are presented as mean \pm standard error. Outlier trials exhibiting investigation times of more than 2 SD from the mean for a given trial were excluded from analysis. In our experience, these outlier trials occur when animals are distracted or frightened by external stimuli. Statistical analyses were performed with SPSS 14.0 (SPSS Inc.). Analyses of variance were performed on all data sets, followed by post-hoc testing using Tukey's HSD criterion $(\alpha=$ 0.05 ) to assess the differences between individual trials.

Table 2. Odors and dilutions

\begin{tabular}{lccccc}
\hline Odor & $\begin{array}{c}\text { Acetic } \\
\text { acid }\end{array}$ & $\begin{array}{c}\text { Propionic } \\
\text { acid }\end{array}$ & $\begin{array}{c}\text { Butyric } \\
\text { acid }\end{array}$ & $\begin{array}{c}\text { Valeric } \\
\text { acid }\end{array}$ & $\begin{array}{c}\text { Caproic } \\
\text { acid }\end{array}$ \\
\hline Symbol & $\mathrm{C} 2$ & $\mathrm{C} 3$ & $\mathrm{C} 4$ & $\mathrm{C} 5$ & $\mathrm{C} 6$ \\
Dilution (\%) & 0.007 & 0.0035 & 0.012 & 0.120 & 0.6 \\
\hline
\end{tabular}




\section{Acknowledgment}

This work was supported by NSF grant no. 0338981 to C.L. and D.A.W.

\section{References}

Barkai E, Bergman RE, Horwitz G, Hasselmo ME. 1994. Modulation of associative memory function in a biophysical simulation of rat piriform cortex. J Neurophysiol 72: 659-677.

Barnes DC, Hofacer RD, Zaman AR, Rennaker RL, Wilson DA. 2008. Olfactory perceptual stability and discrimination. Nat Neurosci 11: 1378-1380.

Bell H, Chenoweth B, Wilson DA. 2008. Neurobehavioral consequences of cortical adaptation disruption during ontogeny. Neurosci Lett 445: 47-52.

Best AR, Wilson DA. 2004. Coordinate synaptic mechanisms contributing to olfactory cortical adaptation. J Neurosci 24: 652-660.

Best AR, Thompson JV, Fletcher ML, Wilson DA. 2005. Cortical metabotropic glutamate receptors contribute to habituation of a simple odor-evoked behavior. J Neurosci 25: 2513-2517.

Buonviso N, Revial MF, Jourdan F. 1991. The projections of mitral cells from small local regions of the olfactory bulb: An anterograde tracing study using PHA-L (Phaseolus vulgaris Leucoagglutinin). Eur J Neurosci 3: 493-500.

Castillo PE, Carleton A, Vincent J-D, Lledo P-M. 1999. Multiple and opposing roles of cholinergic transmission in the main olfactory bulb. J Neurosci 19: 9180-9191.

Chaillan FA, Roman FS, Soumireu-Mourat B. 1996. Modulation of synaptic plasticity in the hippocampus and piriform cortex by physiologically meaningful olfactory cues in an olfactory association task. J Physiol (Paris) 90: 343-347.

Chaudhury D, Escanilla O, Linster C. 2009. Bulbar acetylcholine enhances neural and perceptual odor discrimination. J Neurosci 29: 52-60.

Cleland TA, Morse A, Yue EL, Linster C. 2002. Behavioral models of odor similarity. Behav Neurosci 116: 222-231.

Davison IG, Katz LC. 2007. Sparse and selective odor coding by mitral/ tufted neurons in the main olfactory bulb. I Neurosci 27: 2091-2101.

De Rosa E, Hasselmo ME. 2000. Muscarinic cholinergic neuromodulation reduces proactive interference between stored odor memories during associative learning in rats. Behav Neurosci 114: 32-41.

Duchamp-Viret P, Chaput MA, Duchamp A. 1999. Odor response properties of rat olfactory receptor neurons. Science 284: 2171-2174.

Fletcher ML, Wilson DA. 2002. Experience modifies olfactory acuity: Acetylcholine-dependent learning decreases behavioral generalization between similar odorants. J Neurosci 22: RC201:1-5.

Fletcher ML, Wilson DA. 2003. Olfactory bulb mitral-tufted cell plasticity: Odorant-specific tuning reflects previous odorant exposure. J Neurosci 23: 6946-6955.

Franks KM, Isaacson JS. 2006. Strong single-fiber sensory inputs to olfactory cortex: Implications for olfactory coding. Neuron 49: 357-363.

Grajski KA, Freeman WJ. 1989. Spatial EEG correlates of nonassociative and associative olfactory learning in rabbits. Behav Neurosci 103: 790-804.

Haberly LB. 2001. Parallel-distributed processing in olfactory cortex: New insights from morphological and physiological analysis of neuronal circuitry. Chem Senses 26: 551-576.

Hasselmo ME, Barkai E. 1995. Cholinergic modulation of activitydependent synaptic plasticity in the piriform cortex and associative memory function in a network biophysical simulation. J Neurosci 15: 6592-6604.

Hasselmo ME, Wilson MA, Anderson BP, Bower JM. 1990. Associative memory function in piriform (olfactory) cortex: Computational modeling and neuropharmacology. Cold Spring Harb Symp Quant Biol 55: $599-610$

Imamura K, Mataga N, Mori K. 1992. Coding of odor molecules by mitral/ tufted cells in rabbit olfactory bulb. I. Aliphatic compounds. $J$ Neurophysiol 68: 1986-2002.

Johnson DM, Illig KR, Behan M, Haberly LB. 2000. New features of connectivity in piriform cortex visualized by intracellular injection of pyramidal cells suggest that "primary" olfactory cortex functions like "association" cortex in other sensory systems. J Neurosci 20: 6974-6982.

Jung MW, Larson J. 1994. Further characteristics of long-term potentiation in piriform cortex. Synapse 18: 298-306.
Kadohisa M, Wilson DA. 2006. Olfactory cortical adaptation facilitates detection of odors against background. J Neurophysiol 95: 1888-1896.

Kapur A, Haberly LB. 1998. Duration of NMDA-dependent synaptic potentiation in piriform cortex in vivo is increased after epileptiform bursting. J Neurophysiol 80: 1623-1629.

Linster C, Cleland TA. 2002. Cholinergic modulation of sensory representations in the olfactory bulb. Neural Netw 15: 709-717.

Linster C, Cleland TA. 2004. Configurational and elemental odor mixture perception can arise from local inhibition. J Comput Neurosci 16: $39-47$.

Linster C, Hasselmo M. 1997. Modulation of inhibition in a model of olfactory bulb reduces overlap in the neural representation of olfactory stimuli. Behav Brain Res 84: 117-127.

Linster C, Hasselmo ME. 2001. Neuromodulation and the functional dynamics of piriform cortex. Chem Senses 26: 585-594.

Linster C, Wyble BP, Hasselmo ME. 1999. Electrical stimulation of the horizontal limb of the diagonal band of broca modulates population EPSPs in piriform cortex. J Neurophysiol 81: 2737-2742.

Linster C, Garcia PA, Hasselmo ME, Baxter MG. 2001. Selective loss of cholinergic neurons projecting to the olfactory system increases perceptual generalization between similar, but not dissimilar, odorants. Behav Neurosci 115: 826-833.

Linster C, Johnson BA, Morse A, Yue E, Leon M. 2002. Spontaneous versus reinforced olfactory discriminations. J Neurosci 22: 6842-6845.

Linster C, Maloney M, Patil M, Hasselmo ME. 2003. Enhanced cholinergic suppression of previously strengthened synapses enables the formation of self-organized representations in olfactory cortex. Neurobiol Learn Mem 80: 302-314.

Linster C, Henry L, Kadohisa M, Wilson DA. 2007. Synaptic adaptation and odor-background segmentation. Neurobiol Learn Mem 87: 352-360.

Malnic B, Hirono J, Sato T, Buck LB. 1999. Combinatorial receptor codes for odors. Cell 96: 713-723.

Mandairon N, Ferretti CJ, Stack CM, Rubin DB, Cleland TA, Linster C. 2006a. Cholinergic modulation in the olfactory bulb influences spontaneous olfactory discrimination in adult rats. Eur J Neurosci 24: 3234-3244.

Mandairon N, Stack C, Kiselycznyk C, Linster C. 2006b. Broad activation of the olfactory bulb produces long-lasting changes in odor perception. Proc Natl Acad Sci 103: 13543-13548.

McNamara AM, Magidson PD, Linster C, Wilson DA, Cleland TA. 2008. Distinct neural mechanisms mediate olfactory memory formation at different timescales. Learn Mem 15: 117-125.

Ojima H, Mori K, Kishi K. 1984. The trajectory of mitral cell axons in the rabbit olfactory cortex revealed by intracellular HRP injection. J Comp Neurol 230: 77-87.

Patil MM, Linster C, Lubenov E, Hasselmo ME. 1998. Cholinergic agonist carbachol enables associative long-term potentiation in piriform cortex slices. J Neurophysiol 80: 2467-2474.

Ravel N, Vigoroux M, Elaagouby A, Gervais R. 1992. Scopolamine impairs delayed matching in an olfactory task in rats. Psychopharmacology (Berl) 109: 439-443.

Turchi J, Sarter M. 2000. Cortical cholinergic inputs mediate processing capacity: Effects of 192 IgG-saporin-induced lesions on olfactory span performance. Eur J Neurosci 12: 4505-4514.

Wilson DA. 1998. Synaptic correlates of odor habituation in the rat anterior piriform cortex. J Neurophysiol 80: 998-1001.

Wilson DA. 2000. Comparison of odor receptive field plasticity in the rat olfactory bulb and anterior piriform cortex. J Neurophysiol 84: 30363042.

Wilson DA. 2001a. Receptive fields in the rat piriform cortex. Chem Senses 26: $577-584$.

Wilson DA. 2001b. Scopolamine enhances generalization between odor representations in rat olfactory cortex. Learn Mem 8: 279-285.

Wilson DA. 2003. Rapid, experience-induced enhancement in odorant discrimination by anterior piriform cortex neurons. J Neurophysiol 90: 65-72.

Yadon CA, Wilson DA. 2005. The role of metabotropic glutamate receptors and cortical adaptation in habituation of odor-guided behavior. Learn Mem 12: 601-605.

Received March 5, 2009; accepted in revised form May 7, 2009. 


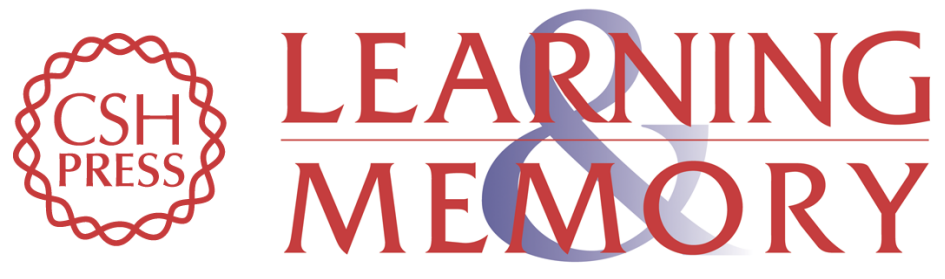

\section{Odor-specific habituation arises from interaction of afferent synaptic adaptation and intrinsic synaptic potentiation in olfactory cortex}

Christiane Linster, Alka V. Menon, Christopher Y. Singh, et al.

Learn. Mem. 2009, 16:

Access the most recent version at doi:10.1101//m.1403509

References This article cites 48 articles, 15 of which can be accessed free at: http://learnmem.cshlp.org/content/16/7/452.full.html\#ref-list-1

License

Email Alerting Receive free email alerts when new articles cite this article - sign up in the box at the Service top right corner of the article or click here. 